\title{
Decks and Other Distinctions: Aesthetics and Class in the Garden
}

ANNA GRUNER

\section{Taste in gardening is an educated love}

The garden provides a kind of lens for understanding individual responses to the broader society. ${ }^{2}$ Looking at this micro level allows an insight into the construction of class in New Zealand. However, in a society that does not officially sanction social stratification, the cues to class may not always be obvious - in a sense, it is covert rather than overt cues that are used to indicate social status. ${ }^{3}$

The New Zealand context makes a study of the domestic garden particularly pertinent. In general, the low residential building densities that have dominated urban centres have meant that, while the size of sections around houses has decreased over time, gardening is still a significant part of many people's experience. ${ }^{4}$ This paper draws on evidence from my study of gardens and gardening conducted in the Wellington region in 2004-05. The study was based around a number of interviews and observations. The eight women and two men who took part ranged from the casually employed living in units with small gardens to professionals with large houses and expansive sections.

To identify and decipher class in domestic gardens, this paper draws on the work of Pierre Bourdieu, especially his studies on the relationship between consumption and class stratification. ${ }^{5}$ In his work, Bourdieu highlights the way in which leisure and consumption are implicated in, and help reproduce, class inequality. His approach involves teasing out the relationship between the economic and symbolic dimensions of class stratification. In particular, it is the symbolic dimensions of class which provide the focus of this paper.

\section{Primacy of the visual}

Ornamental gardens are created to be visually consumed. They are primarily aesthetic in nature. Bourdieu argues that judgements of aesthetic taste contribute to, and reflect, the social order. ${ }^{6}$ He argues that 'distinction' is the ultimate embodiment of an educated and cultivated disposition, in which the lifestyles and aesthetics of the elite are distinguished from those below them in the social hierarchy. The aesthetic choices the participants in my study make in their gardens in relation to ornaments and fashion trends thus locate them in social space and distinguish them from each other. 
The significance of aesthetic choices can be understood within the context of the increasing importance of visual experiences in the modern world. Lefebvre has argued in his The Production of Space that in modern society the visual sense has gained the upper hand and that impressions derived from other senses have faded into the background? Thus social life becomes based on the decipherment of messages received by the eye.

From my own observations and interviews, it is clear that visual experiences are increasingly emphasised in New Zealand domestic gardens. In the gardens I visited, the emphasis on the visual was reflected in the gardens' structure and organisation. While each of the gardens was 'ornamental' to some degree, in that every one reflected the aesthetic taste of its gardener rather than being purely utilitarian, there was a continuum among the participants in the degree of attention to the visual consumption of the garden. This ranged from those with general concerns over the look of their gardens, to those who carefully structured their gardens specifically for viewing, with seating areas from which people could survey and admire the garden. Rather than exemplifying a primary concern with practicality or a physical engagement with the plants and the soil, gardens were often structured to create a visual impact. Plants were subordinated to the effect they created as a garden backdrop. ${ }^{8}$

To create a garden, however ornamental, does nonetheless require a physical engagement with the land, and the gardeners I interviewed all saw physical work in their gardens as important. Most saw this as an enjoyable aspect of having a garden. Tessa told me that she likes 'a bit of hard yacker', while Sarah said, 'I garden because you are actually doing something, as opposed to sitting and watching'. Rosemary commented, 'I do like the physical aspect of it'. Yet, ultimately, an ornamental garden is all about visual enjoyment. I suggest that if there were no end product to enjoy, especially through visual consumption, people would not make ornamental gardens. This visual emphasis in gardens is also reflected in the way guests are invited into gardens to admire their beauty, not to weed beds, clip hedges or mow lawns.

The importance of the visual aspect was reflected in participants' comments about their gardens, as well as in the way in which gardens were physically structured and displayed. Here, decks have a significant role to play.

\section{Decks and other viewing structures}

Five out of ten participants I interviewed had linked their house to their garden with a deck. While it has been argued that the conservatory can be seen as 'bringing the outside inside', ${ }^{\text {I }}$ would suggest that in New Zealand the deck can be seen as 'bringing the inside outside'. The deck, as an 
extension of the house, takes elements of the inside domestic sphere into the garden. The deck thus becomes a liminal area, a space that lies physically between the house and the garden. As such it is a not-garden, not-house region in which indoor social activities are allowed to spill out beyond the living room without touching the lawn or encroaching onto the flowerbeds. The deck supports activities such as entertaining and eating outdoors. In terms of the visual nature of domestic gardens, decks are important because they display the garden from a particular viewpoint, presenting a certain aesthetic.

All the decks of my participants shared a number of common features. The decks were all directly accessible from inside the house via an external door (often a French or glass door), they were constructed on the same level as the house itself and they all faced the back garden of the house, producing a degree of relative privacy. On each deck were a number of pieces of outdoor furniture, essentially seats and a table. From each deck there was a view of part of the garden and, in two cases, a view beyond the garden.

These attributes communicate a number of things to those invited onto the deck. The setting informs visitors what to do, where to sit and how to look out on the garden. It provides a foundation for consuming food and drink while also consuming something else: the view of the garden. As a staging of the garden, the deck floats above the landscape, an extension of the house from which to survey the back yard. ${ }^{10}$ It provides a basis for viewing the garden, an elevated vantage point that allows a specific view (Figure 1).

The view from all the decks in my study is of the middle area of the garden. Ideally, all utility areas are kept out of sight and a relatively manicured area is in view: "in a sense, this is a display of the labor that has gone into the garden.." However, while it is a display of labour, the actual signs of labour must not be visible. Items such as tools and other equipment are removed from view. On display is a finished product that the labour input into the garden has created: well-cared for garden beds, mowed lawns, clipped hedges.

Staging the garden from a particular vantage point thus encodes the aesthetic that the owner wishes to convey. From the deck, the viewer is directed towards an aesthetic that focuses primarily on non-utilitarian features, in particular, plants and plant combinations. The ideal aspects of the garden are on display from the deck, and the deck becomes the perfect place for the middle class to display and communicate their status (Figure 2).

In the process the garden is relegated to a safe distance and is, in a sense, rendered passive. The garden becomes a backdrop for display on 


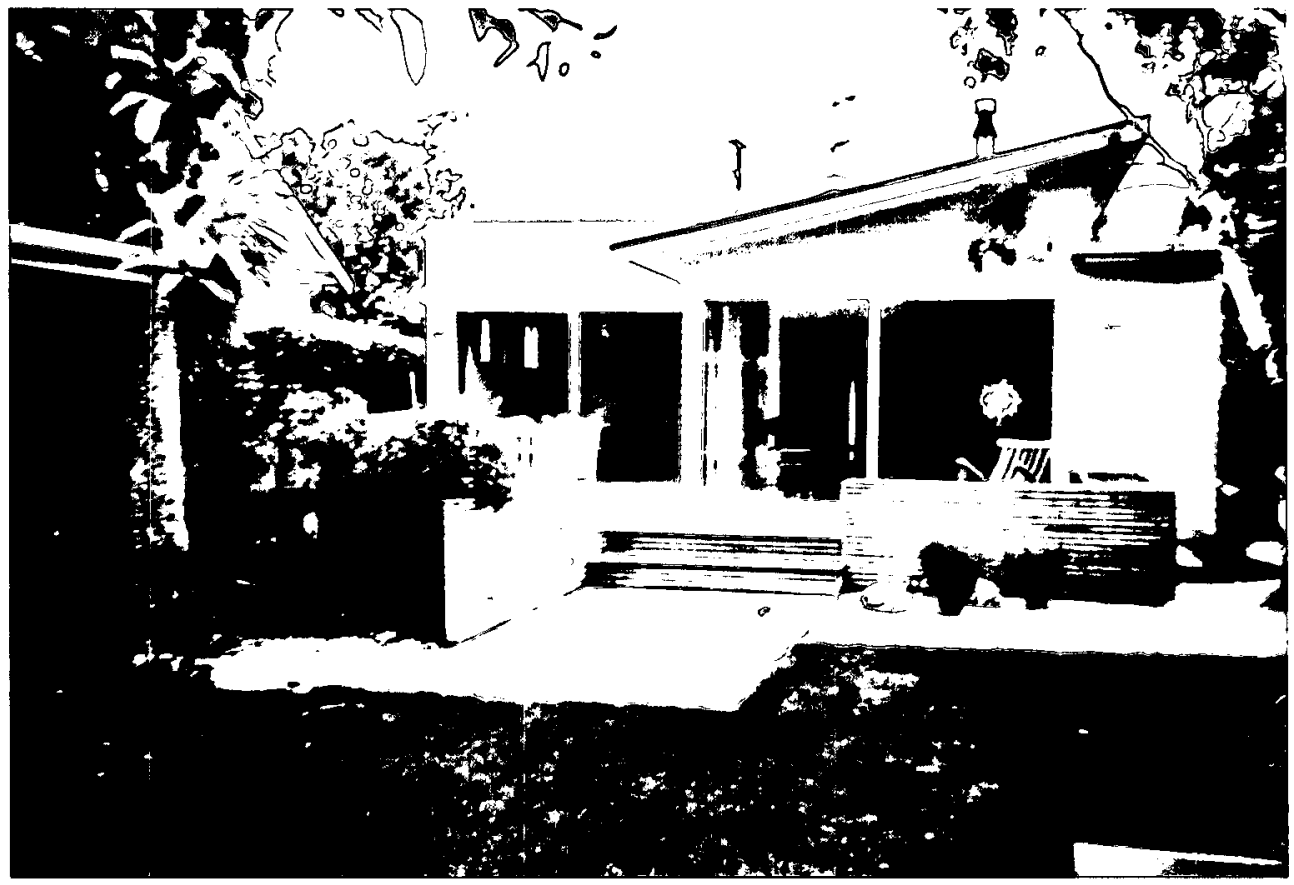

Fig 1: A typical deck overlooking the back garden.

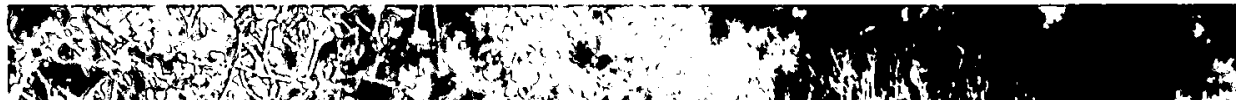

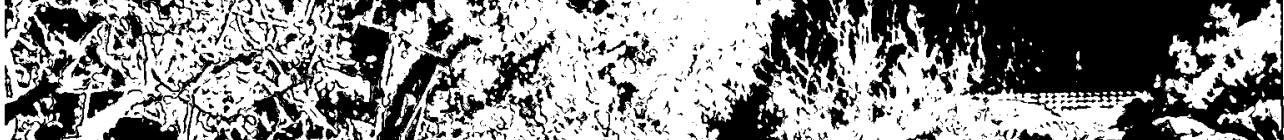

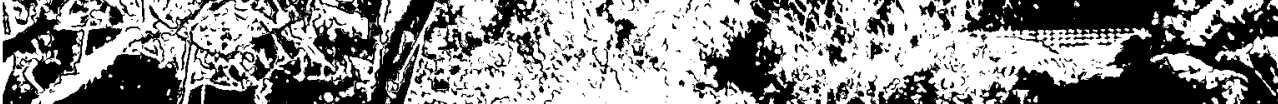

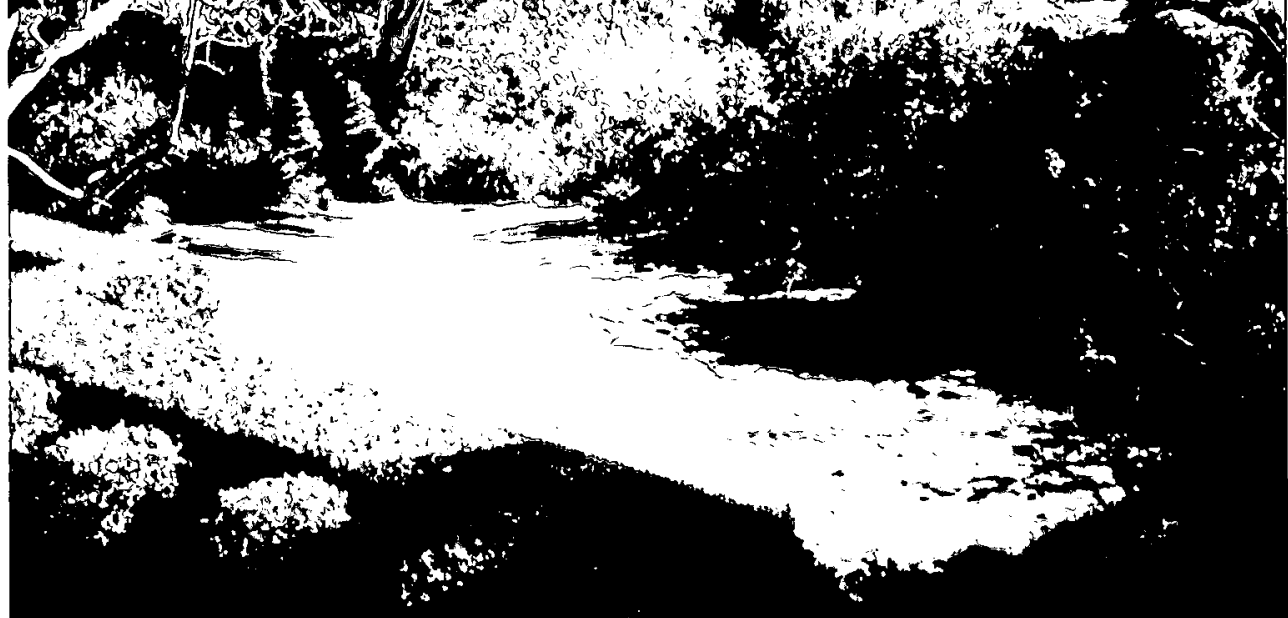

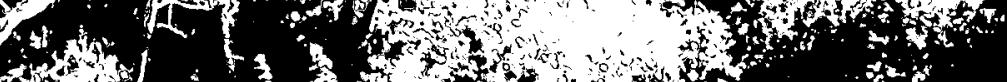

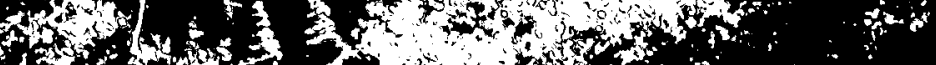

Fig 2: Clipped topiaries and hedges and the freshly cut lawn provide a non-utilitarian view from the deck. 
Fig 3: Carol's outside seating area, a convenient place for smokers.

social occasions. Rather than encouraging people to sit on the lawn, which would involve entering into a tactile as well as a lowlevel visual engagement with the garden, decks provide an elevated vantage point and keep the physical reality of the garden at a distance. ${ }^{12}$

On the other end of the continuum, a number of participants did not have decks, although they did have a variety of other arrangements. Tessa had a veranda, and on this were two chairs and a table. This was clearly a location for leisure, but it was also combined with utility in that it was the main area for

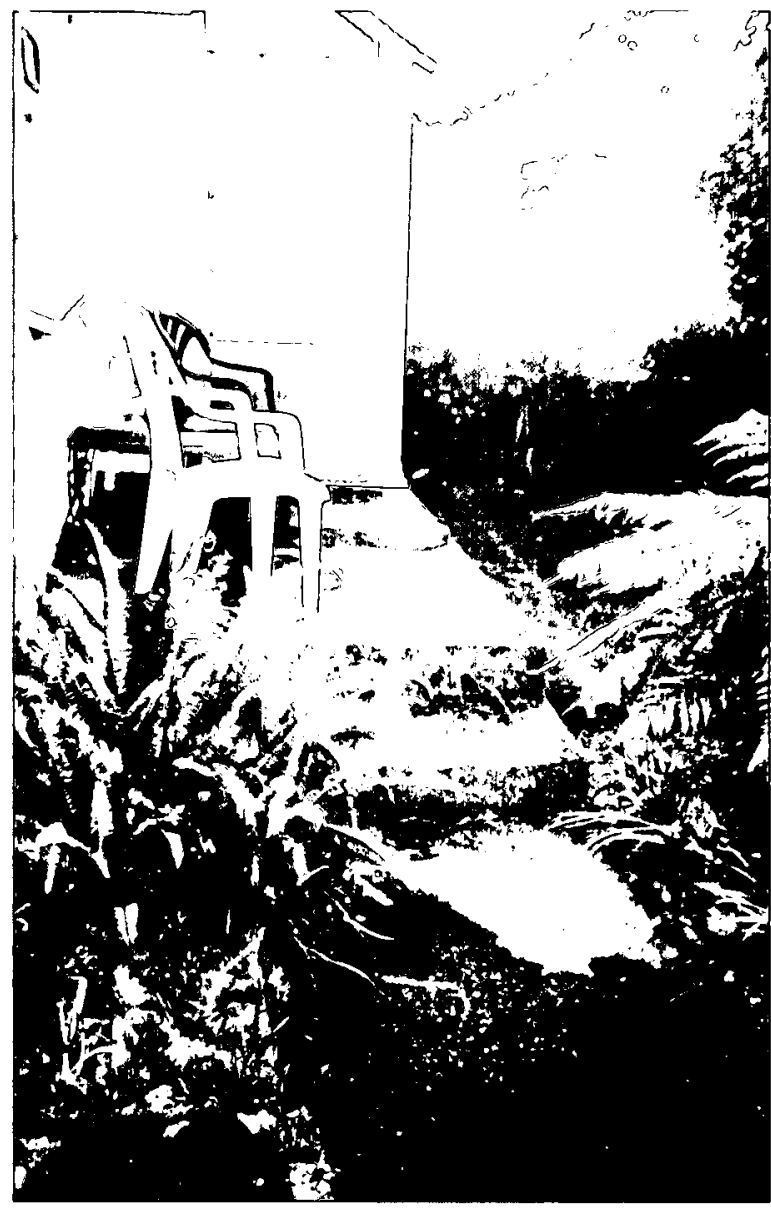
raising seedlings, many of which were on a small table located between the chairs.

A nother participant, Carol, had three plastic chairs and a low table placed on a small elevated concreted area outside the house facing the back garden (Figure 3). When discussing the social uses of her garden, Carol said:

In the summer, on very, very hot days, I sat out there, like when Daphne came round, or when other friends came round, we went and sat out there. Mostly because they are smokers - not all of my friends are smokers, but the ones who smoke...

This comment highlights that this area is used for an activity that is not permissible in the house, rather than the importance of sitting outside.

Rose had a bench seat on a concreted area behind her house. This was the most private place to sit in her relatively open section. The view from the seat was predominantly of a concrete-block retaining wall in which 


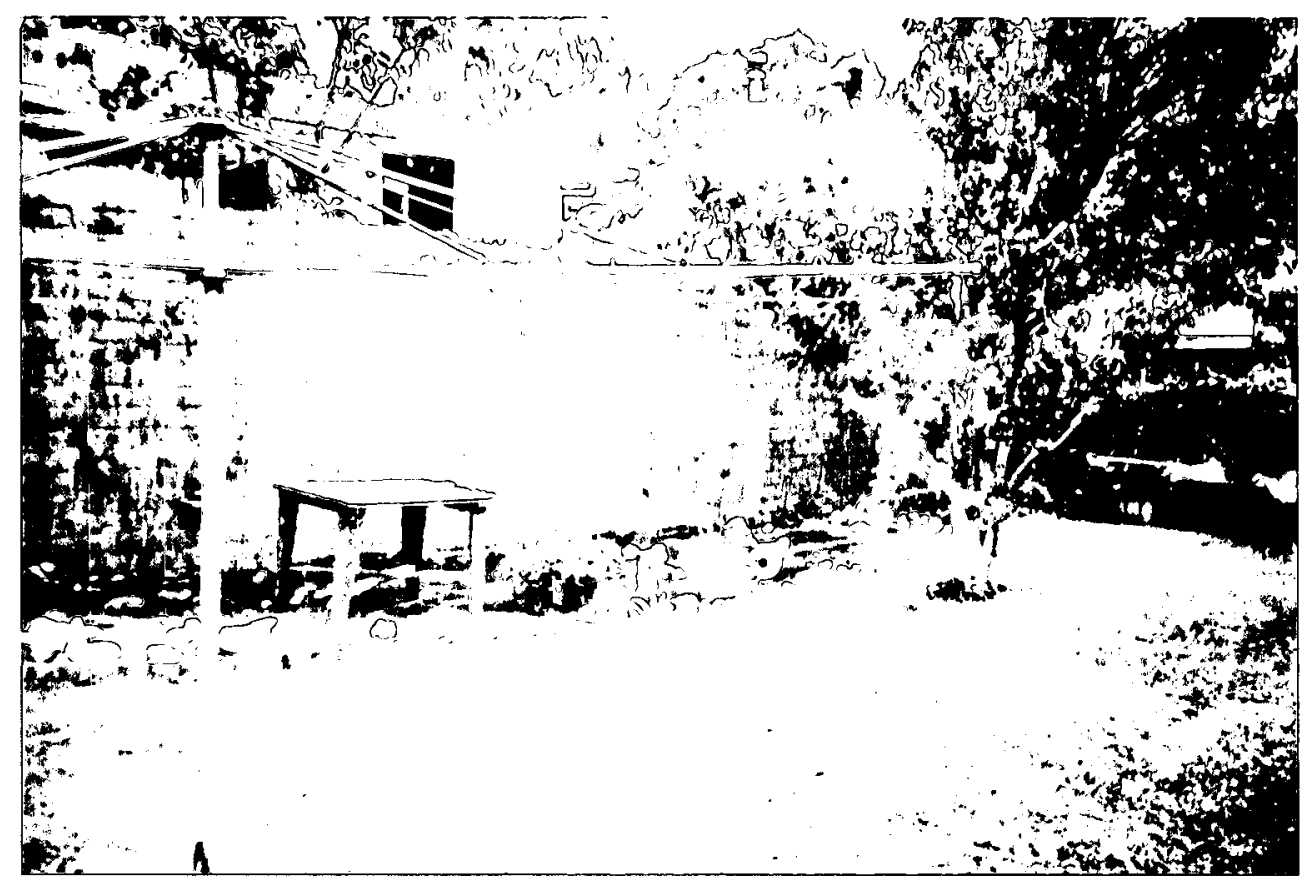

Fig 4: No outside seating in Janet's garden.

flowering and leafy plants were growing. When I asked her if she spent time in the garden socialising with friends, she replied:

There really isn't the place [for it]. Apart from just outside the back, and, yeah, we occasionally sit out there. But mainly I visit their gardens, which are bigger and sunnier.

Janet, on the other hand, had no outside seating at all. In her case, friends and family were rarely taken into the garden as there was nowhere to sit, relax, eat or drink (Figure 4). The only way to access Janet's garden from her house was to walk through the kitchen and out the back door. As Janet noted: 'Because [of] the way it's situated you don't go into the garden [with visitors|. They come into the house straight away.'

Comments such as these tell us about the different social uses of gardens. But these comments, and the way the gardens themselves were structured also tell us something more - about the people that created them and about class. Those participants with decks shared a middle-class disposition that valued a highly ornamental garden, where the viewer is directed towards the most ideal and non-utilitarian aspects of the garden from the deck. On the other hand, more working-class participants were not so concerned with their gardens being viewed from one clear vantage point, and instead areas for seating tended to be convenient, rather than purpose built for viewing, with utilitarian areas of the garden more likely to be in view. 


\section{Garden 'art'?}

Given the different kinds of emphasis on the visual in gardens, aesthetic choices are clearly paramount. The general theme of Bourdieu's Distinction is an attack on the Kantian approach of 'pure aesthetics', which sets aesthetic judgement apart from other forms of discrimination and attributes to it a particular quality of purity. Whereas the Kantian approach to aesthetics suggests that high cultural objects have some kind of intrinsic quality and worth, and that aesthetic judgement is somehow 'disinterested', Bourdieu argues that the 'pure' gaze is a historical invention and that there is no objective means of prioritising one form of practice or object over another. Instead, judgements of taste and distinction are seen as social constructs that come to function as markers of class. ${ }^{13}$

The use of garden ornaments by participants in this study offers another means to examine aesthetic choices and social distinctions in

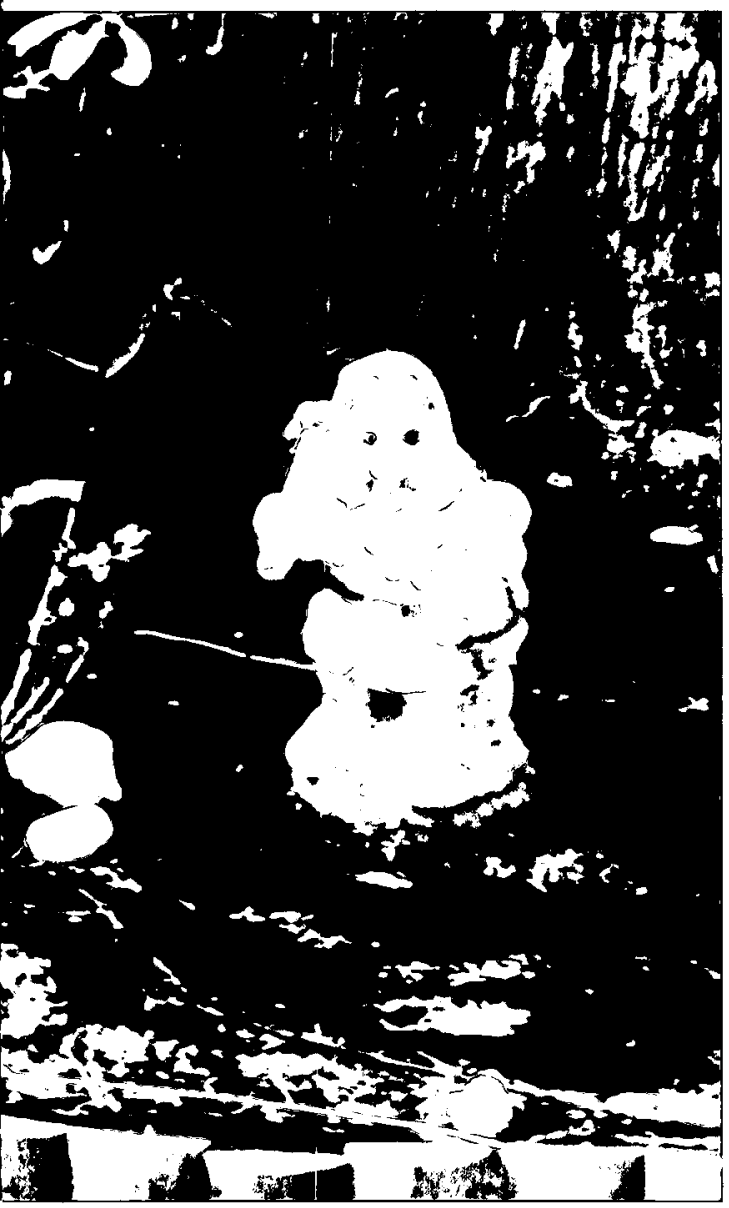

the context of the domestic garden. Janet's garden had small models of animals, such as a dolphin and a rabbit, made out of concrete, as well as a number of gnomes, including the one at left (Figure 5). A nother gnome was sitting on a plaster can, and when I asked Janet about this, she replied that it was a 'Tui can .... it's a Tui gnome, he's groovy'. This was a reference not to the New Zealand native bird, but a brand of beer. Nonetheless, this was not seen as negative as it would be by more middleclass people, and the gnome was displayed on the flowerbed and was discussed in a positive way.

Rosemary, a semi-professional artist, had a number of her own creations, largely made out of pumice and recycled timber, on display in her garden. She

Fig 5: One of Janet's garden gnomes. 
mentioned that "quite often I have a little school of fish' created out of pumice and mounted on stakes in the garden. Other participants also talked of wanting ornaments in their gardens. Sarah, after telling me that she liked the idea of making a wind feature, said: 'we've been thinking about Len Lye wands'. The reference was to the sculptures of a well-known New Zealand artist. Her mention of his name linked her cultural knowledge back into her own domestic garden. Sarah suggested that, rather than buying something by such an artist at massive expense, her partner may be able to create something similar himself. This potential ornament she referred to as 'the sculptural piece'.

John also discussed 'sculpture' in his garden. Set in the centre of his camomile lawn was a sculpture of a tall, thin woman (Figure 6). He told me:

That's a Rebecca Rose ... I think that was the best series that she did actually. It was her first series, mind

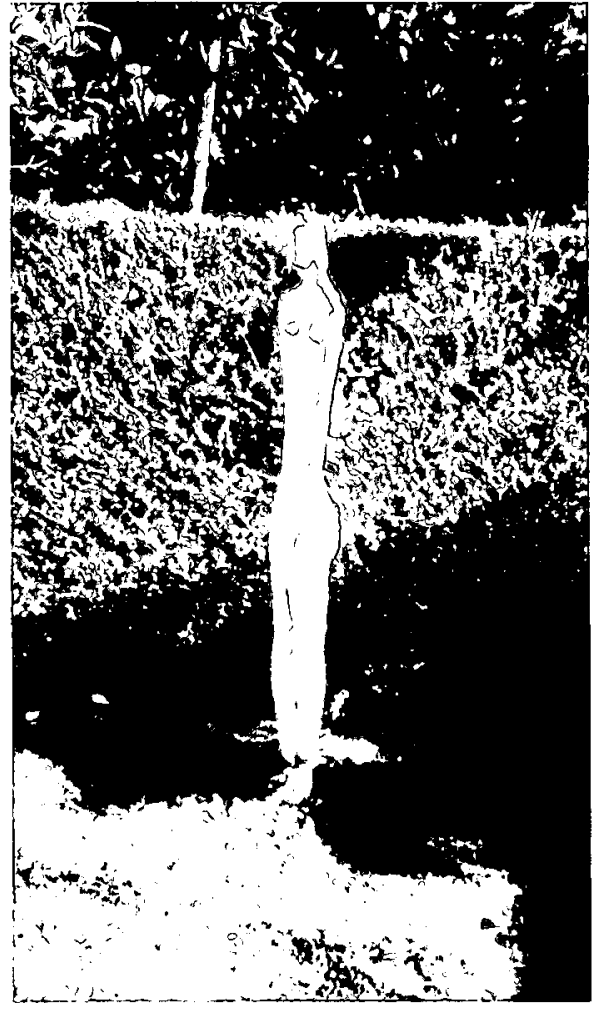

Fig 6: The sculpture by Rebecca Rose in John's garden.

you, it was a real steal, I think something like 250 dollars ... It was incredibly good value ... And she delivered it to the site.

John's statement displays specialist cultural knowledge and a certain level of discernment, and hints at a personal link with the artist. It recognises the artist's value in the art world, but through his reference to the artist having visited his garden, a direct link is also made to the world of art. Such a visit may be seen as a symbolic transferral of the artist's status onto John and his garden. Furthermore, John later went on to say that the sculpture reminded him of the Swiss artist Giacometti and his sculpture the 'Walking Man'. Such a reference not only displays John's knowledge of what is considered legitimate art in New Zealand, but also reveals a more general knowledge of the art world and his capacity to link local and international artists.

The various ornaments that these participants had, and the way they were discussed, were linked to the structure and form of their gardens. It would 
be difficult to imagine gnomes in John's garden (unless as an ironic joke at the expense of working-class taste) $)^{14}$ or a wind sculpture in Janet's garden. Aesthetic choices in the garden, including ornaments, reflect broader cultural practices. They are engendered by the same general dispositions as eating preferences, dress styles, sporting interests and other facets of day-to-day culture. As Codd notes, Bourdieu sees such cultural practices as creating systems of classification which structure aesthetic perception and judgements of taste. ${ }^{15}$

Thus certain ornaments are referred to as works of 'art', while others are not. This is because works of art only exist as symbolic objects if they are known and recognised. They must be socially instituted as works of art and received by spectators capable of knowing and recognising them as such. ${ }^{16}$ When writing about the social uses of art, Bourdieu reveals how aesthetic distinctions are constructed to maintain social difference and distance. ${ }^{17}$ John, in choosing to display a sculpture of a known artist, sustains a differentiation from Janet, who is unlikely to know the artist or recognise her work.

Bourdieu argues that aesthetic distinction is produced by deceptively ascribing aesthetic value to objects, thus circumventing the contingencies of the market and elite networks that sanctify such attributions. The symbolic ascendancy conferred on cultural productions is expanded as their privileged qualities become bound up with, and finally intrinsic to, the social categories of people that have sponsored and appropriated them. Although this process is eminently social, it appears to be a game of objective qualities, related to emotive discussions and feelings of pleasure. As a social process, distinction thereby becomes so inarguable as to be regarded as inevitable. ${ }^{18}$ Thus it is inevitable that an ornament referred to as a 'sculpture' or by the artist's name will be superior to a garden gnome. While the former is 'art', the latter is simply a garden ornament with little distinctive financial or aesthetic value.

The drawing of distinctions between art and non-art is the task of 'specialists'. But other 'less disciplined' kinds of aesthetic production thrive. ${ }^{19}$ These may be referred to as 'un-legitimated' forms of aesthetic creation. Some participants thus made aesthetic choices without reference to legitimated cultural norms. They stated simply what they liked in a garden, whether it was garden ornaments, colourful flowers or the size of trees. In their gardens, aesthetic production was often linked with access to resources such as inexpensive garden materials or free plants, but was rarely discussed with reference to styles or trends. As Regina Bendix found in her study of gardens in Portland, Oregon, gardens do not necessarily adhere to elite categories of artistic creation. ${ }^{20}$

In fact, one of the participants in my study, Rose, clearly saw the very idea of gardening styles as pretentious. When I asked her if she would define her garden as having a style, she commented: 
No. I mean it doesn't have 'rooms' ... I have seen it on gardening programmes ... They have 'oh this is the room' . . There's no gazebo in sight in my garden; no archways, nor is there any art . . . No, it's your bog standard, rented accommodation. [1] stick a few things in so the place doesn't look so grotty.

Rose recognised that there are people very concerned with style and fashion, but she contrasted herself to them by claiming that she was engaged in a different activity. She saw herself as after simple beautification without elaborate structures or art. Rose was in fact distancing herself from those participants consciously aiming to create a style and to include 'sculpture' in their gardens.

\section{Aesthetic whole or parts in the garden}

For those participants that were aiming to establish a particular style in their gardens, this required creating an overall effect, constructing a particular landscape where everything fitted together. This was clearly the aim of some participants, especially those with tertiary education and/or with parents who were professionals. They were concerned with establishing an integrated garden design. For them, different elements in the garden had to be connected.

Sarah commented that when her partner was putting in steps to connect different parts of the garden:

he was just going to put concrete steps in and I wouldn't let him. No, I said, [they] had to match that [stone wall next to the steps] . . I said they had to be stone.

When talking about his garden, John also emphasised ideas of continuity and of tying things together, of balance and the importance of design and structure. He commented that he was trying to:

tie one area in with the next, by using perhaps the same plant into the next garden, or one of the same plants ... to tie it through into the next bit.

The idea of unity as an ideal of garden design is widely discussed in gardening literature. Unity is explained as a linking of different parts of a garden into a whole so that nothing stands out and appears as if it does not belong. The different parts of a garden must be inter-linked. ${ }^{21}$ Gardening magazines often appeal for an 'overall look'. An article in the monthly magazine New Zealand Gardener suggests that the look of a garden can be reinforced by selecting materials with 'suitable' tones and textures. In the process of 'exterior decorating' a garden,,$^{22}$ no less energy should be spent than on choosing colours and textures inside the home, as this is 'as close as gardening comes to interior decoration'. ${ }^{23}$ Michael Bligh, writing on 'creating 
your garden', similarly suggests that 'there should be a good reason for the choice and placement of every plant' to contribute to the 'overall design'. ${ }^{24}$ These attitudes essentially indicate that there should be an adherence to a particular style. In order to create a certain style as well as unity in a garden, where different components combine to form a single integrated whole, a particular legitimated knowledge is required to understand what constitutes style and how to recreate it in one's own domestic garden.

But as discussed above, not all participants shared this knowledge and some openly rejected such ideas as pretentious. To Janet the very idea of her garden having a style, or that she followed a particular design, was seen as ludicrous. When I asked her if she saw her garden as having a style, she said, laughing, 'No. No style at all! . . . A wee bit of planning, but no style.'

Those participants who rejected the idea of their gardens conforming to a particular style appeared to have little sense of their gardens forming unified 'wholes'. Instead, they conceived of the different elements of their gardens as separate parts. A garden made up of disparate parts was most evident in Janet's case. Natives were mixed with exotics, and flowers with bright colours were grown next to each other without any apparent concern as to how they fitted together. In Janet's garden, as in those of some other participants, there was a strong emphasis on colour. Flowers were chosen for their bright colours rather than for their ability to fit into a design or create linkages and contribute to an overall effect.

\section{Changing fashions}

Aesthetic choices may, of course, be influenced by changing fashions. How participants aligned themselves to trends in fashion may also be understood as part of a process of social positioning. It reflects their access to, and understanding of, legitimised views of what was considered as current taste, as well as what constituted garden styles which were no longer fashionable.

\section{The cottage garden}

The term 'cottage garden' brings to mind an image of a thatched cottage, a mass of honeysuckle round the door and climbing roses clustering around the windows. On either side of the path leading to the front door there are flowers and rosy-cheeked children playing on the doorstep. ${ }^{25}$ This kind of idyllic cottage garden, reproduced on innumerable postcards and chocolate boxes, has been shown to be based, at least partly, on myth, but gardeners have converted it into reality for more than a century. ${ }^{26}$

The cottage garden continues to be important, and in many of the interviews I conducted in 2004 it came up as a topic of discussion. For some participants it was clearly something that belonged to the past, while 
for others it was still an aspiration, an ideal to work towards in their garden. Interestingly, the majority of the participants who saw the cottage garden as an aspiration had a parent who worked in a relatively low-status occupation - in a trade or as a sales person, for example - and three out of five had low to medium incomes and were employed in areas such as retail and manual labour. Comments about desiring a cottage garden were sometimes quite explicit. Tessa told me of her plans for her front garden: she wanted daisies and foxgloves and dahlias, saying a "cottage garden is really what I'm . . . trying to do'. At other times, participants made more indirect references to the cottage garden style, saying they liked a 'rambly overgrown' garden or a 'rustic look'.

Those participants who saw cottage gardens as passé had all previously had cottage gardens, but they had either moved to a new property and garden or converted their existing gardens away from this style. Petra had moved house and eliminated all signs of a cottage garden by concentrating on greenery and foliage, retaining only a minimum of flowering plants. She remarked that:

I like the different shades of greens, you know. I think that makes it

[the garden] very interesting. No flowers, I didn't want [that] any more, because 1 had a cottage garden at my previous house.

Rosemary commented simply that she has stopped bringing cuttings and flowers into her garden: 'I've sort of got rid of that, as I've gone more and more into natives.' John was the most forceful about his dislike of cottage gardens. He told me, 'I get quite bored going to gardens where they all look the same, they're all cottage gardens, we've all been there.' Having moved away from the cottage garden style, these participants were now engaged in new, contemporary fashions that concentrated on foliage, shape, texture and natives.

\section{Contemporary fashion: natives and foliage}

The trend of growing natives ties into a general movement away from colourful annuals. Many place increasing emphasis on shape and texture rather than colour and variety. Anne Barker, writing for Your Home \& Garden, states that 'natives are hot news for landscaping ... [with] bold forms and textured foliage' ${ }^{27}$ Recognition of the distinctive form of many native plants has led to their increased use in contemporary gardens. Species such as cabbage trees, flax, libertia, puka and others are being incorporated in a variety of ways. Corokia, hebes and pittosporum have suddenly become very desirable plants, for both clipped or informal hedges and screens ${ }^{28}$ Furthermore, now that reducing the time spent gardening is considered a good thing, native plants are often seen as the first choice for low-maintenance gardens. ${ }^{29}$ 
All the participants who took part in this study had a number of native plant species growing in their gardens. It was the view taken of natives, or the emphasis placed upon them, however, that varied. Rosemary had a garden structured around native trees, and she characterised her garden as a 'New Zealand garden . . . using New Zealand plants'. Puka, ferns, cabbage trees, pohutukawa, lancewoods and rimu were just a small number of the native plants in the garden, and she told me, 'I love native trees.'

John's garden also incorporated a large number of native species, and this was linked to his desire to use as many natives as possible:

My aim is to try and create something new, [to] use as many New Zealand plants as I can. I find it difficult using all New Zealand plants but . . . we're lucky to have this huge, magnificent backdrop of beech and rimu, and kahikatea . . . a lot of pittosporums and ... kowhais . . . which are stunning . . . to garden through.

In contrast David, Janet, Rose and Carol had some natives in their gardens but when discussing their gardens, they placed little emphasis on them. When telling me about their most valued or favourite plants, natives were not mentioned at all.

Combining with the trend in natives, many gardening and fashion magazines feature photos of contemporary gardens that illustrate a style predominantly focused on foliage, texture and structure, often incorporating grasses and succulents along with stones and pebbles. Only a few of the participants I interviewed reflected an awareness of such current trends. When 1 asked Petra what her favourite plants in her garden were, she said: 'I like grasses at the moment. Various grasses; I think they are lovely.' John had created a garden that he referred to as 'sculptural'. After having removed most aspects of the cottage garden style, he said of the bottom garden, 'now I'm going into . . . just keeping green and shapes, that's virtually what I'm going to work to there.' In general his garden had topiary, limited use of colour and clipped hedges. He saw the hedges as particularly important:

It's hard to live away from the box [shrub], that's for sure . . I think hedges are fantastic in gardens . . . They're living . . . they add shape, they keep the structure and they hold the garden together.

Other participants, such as Tessa, Janet, Carol, David and Rose, did not reflect any of these popular contemporary fashion features in their gardens. In contrast to those who valued texture and foliage, these participants highlighted the importance of bright coloured flowers. Carol commented, 'I love begonias - well, who wouldn't love begonias? They look so beautiful!' These participants had flower gardens that the others would potentially judge negatively. Rosemary, for instance, stated: 'I'm not so mad on little pretty flower gardens', and Sarah said: 
I hate little gardens with little tiny low plants. Like straight driveways, and a row of plants down the side, and a row of plants in front of the house.

It is judgements such as these that generate acts of cultural distinction that distance participants from one another.

\section{Media and knowledge}

To be aware of garden fashions requires knowledge and understanding of what is currently seen as the 'legitimate' way of designing and developing a garden. This knowledge is gained from watching television shows, visiting other gardens open to the public, as well as by reading current publications on gardening, particularly the major monthly gardening magazines. Some participants showed little interest in reading such publications. Janet, when asked if she reads about gardens or gardening, responded: 'definitely not magazines . . . The odd book yeah . . . if I want to find something out pretty much, not for entertainment.' Tessa also reported spending little time reading and added:

I kind of like talking about it ... with other people and steal their ideas. But I've got the Yates gardening book that I inherited from my grandparents, so that's probably from 1959 or something. And I look at that. I think they're still valid things.

Her statement reflects little concern with fashion trends and reading about new developments.

In contrast, when I asked Petra if she reads publications on gardening, she answered enthusiastically, 'masses . . . Although I'm pretty much finished with the design, I still love to look at garden designs.' So-called 'experts', such as magazine columnists, have come to define the legitimate aesthetics of modern gardens. Gardening magazines and books on gardening, however, are not inexpensive and therefore were most easily available to, and most read by, the three participants with the highest annual family incomes. Their relatively high incomes, along with their knowledge gained through social origin and education, allowed them to establish a greater competence in relation to legitimated garden aesthetics and what is considered fashionable. Not surprisingly, it was these three participants who incorporated elements of current fashion trends in their gardens.

In gardening publications, there is often a distinct sense that by reading and putting into practice what writers suggest, gardeners can advance up some unspecified ladder of gardening consciousness. As in many discussions of aesthetic taste, notions of simplicity and purity carry moral overtones of self-denial in the name of a higher state of being. ${ }^{30}$ Belinda Probert points out that this may arise from the many English-speaking garden writers who have similar social origins, creating a 'dominance of the upper classes in 
defining taste, meaning and practice'. ${ }^{31}$ Only people who have access to these definitions know how to interpret and rank gardens according such criteria. With this, comes an ability to judge what is and what is not a 'successful' garden and the correct language to pass judgement on others' gardens. Thus John was able to speak about gardens that he had visited and that he viewed as unsuccessful, as well as those that conformed to his idea of a 'good' garden. This type of interpretation and judgement highlights his knowledge and provides him with a sense of distinction because it draws upon his understanding of aesthetics and what is correct and fashionable.

\section{Conclusion}

Landscape, Nicholas Green argues, is engaged within a materially-located process of perception and identification. ${ }^{32}$ It involves a two-way dialogue that works to shape social identity. The organisation of space is already coded in the way it is experienced, which allows for varying 'ways of seeing ${ }^{33}$ that mould the experience of space, and through which space moulds social relations. ${ }^{34}$ I suggest that such materially-located processes of perception and identification were also at work in the domestic gardens in this study.

Participants in similar class positions shared common ideas about garden fashion, and thus located themselves within a subculture based around particular ways of seeing and being. Decks were owned predominantly by the participants with professional occupations and relatively high incomes. Socialising on the deck - with all the appropriate trappings of right furniture and right food - overlooking the well-cared for garden is indicative of middle-class sensibilities. Entertaining guests while looking out at the garden is particularly common among the middle classes, and is even more important as an ideal. In the Wellington region, the difficulties of dining or relaxing outside in an often windy environment may mean that the deck has an even higher sign value than use value - that decks can, in fact, be understood as statements of class rather than as objects of use. Many of the participants with decks also perceived cottage gardens as outmoded and lacking style, whereas those without decks often aspired to a cottage garden. Through these types of categorisations, participants can be socially identified. As Kate Fox notes in relation to the English and their gardens, the design and content is "largely determined - or at least very strongly influenced - by the fashions of the class to which he or she belongs, or to which he or she aspires'. ${ }^{35}$

While the process of class identification and perception is materiallybased, it remains complex. Some participants had parents with no tertiary education who worked in manual or low-skilled jobs, but the participants themselves were better educated and engaged in higher status employment. Such participants were involved in a process of perception and identification 
that was both working class and middle class. Thus Petra had a garden that was structured according to middle-class ideals of display and aesthetics, yet she had no sculptures or pictures by known artists in her house or her garden. These would have provided clear signs of instinctively having the 'right' middle-class taste.

Gardening as a form of cultural practice involves appropriation rather than mere consumption. Thus while cultural stratification is, in part, determined directly by the unequal distribution of economic capital and therefore also of cultural goods, there is something more important taking place. Highly significant is the way in which objective class distinctions are internalised as differing dispositions, differing abilities to utilise cultural objects, which produce different logics of cultural practice. ${ }^{36}$ Such differing dispositions help to create different gardens.

Bourdieu argues that at every level above the working class, people are making aesthetic distinctions to separate themselves from those below them in the social hierarchy. In fact, Bourdieu goes so far as to suggest that in the system of aesthetic positions the sole function of the working class is to serve as a negative reference point in relation to which all aesthetics define themselves by successive negations ${ }^{37}$ But while Bourdieu does not allow for working-class distinctions of beauty - this being exclusively the realm of the middle and upper classes - I would suggest that this is not the case. The working-class participants in this study also spoke of beauty and of enjoying the visual aspects of their gardens, but for them beauty was found in bright colours and common ornaments, rather than in the 'art' and fashions of the middle class.

However, in the battle for distinction, Löfgren suggests that '[g]ood taste needs vulgarity and tastelessness to hedge its own territory', ${ }^{38}$ which may result in working-class ideas of beauty being classified by others as tasteless and/or outdated. Such judgements derive their value from their potential to generate acts of cultural distinction or demarcation. The basis of aesthetic taste is found in a principle of social closure whereby groups try to improve their accumulation of cultural capital by excluding other groups. ${ }^{39}$ Thus as Simmel reminds us, fashion "unites those of a social class and segregates them from others. The elite initiates a fashion and, when the mass imitates it in an effort to obliterate the external distinctions of class, abandons it for a newer mode. ${ }^{90}$ What was considered beautiful may come to be seen as kitsch, or what was once a fashionable garden style may come to be seen as passé. As the cottage garden becomes 'common' (both in being widespread and ordinary) it is superseded by a new fashion concerned with foliage, texture and natives.

The very idea of a garden being an aesthetic object is a sign of social distinction; its absence is likewise. Aesthetic positions adopted by people in 
relation to the house and garden are 'opportunities to experience or assert one's position in social space, as a rank to be upheld or a distance to be kept'. ${ }^{41}$ David Miller has noted that in societies that place a relatively high importance on achieved as opposed to ascribed status, the "externalisation of selfhood' becomes particularly important. The relative absence of institutionalisation of social position is associated with an emphasis on turning oneself into an object for the gaze of others, in order to know who one is ${ }^{42}$. Thus taste in gardens can be seen as a self and other classificatory system. As Bourdieu argues: ' $[t]$ aste classifies, and it classifies the classifier, ${ }^{, 3}$

1 F.R. Cowell, The Garden as Fine Art: From Antiquity to Modern Times, London, 1978, p.221.

2 M. Bhatti and A. Church, "'I never promised you a rose garden": gender, leisure and home-making', Leisure Studies, 19 (2000), pp.183-97

3 J. Duncan, 'Landscape taste as a symbol of group identity', Geographical Review, 63 (1973), pp.334-55.

4 H.C. Perkins and D. Thorns, 'Houses, homes and New Zealanders' everyday lives', in C. Bell, ed., Sociology of Everyday Life in New Zealand, Palmerston North, 2001, pp.30-51.

5 See P. Bourdieu, Distinction: A Social Critique of Taste, London, 1984.

6 Bourdieu, Distinction.

7 H. Lefebvre, The Production of Space, Oxford, 1991.

8 Bhatti and Church, in their study of domestic gardens in the UK, argue that a similar shift to visualisation has also taken place in English domestic gardens. M. Bhatti and A. Church, 'Cultivating natures: home and gardens in late modernity', Sociology, 35 (2001), pp.365-83. For further discussion on the primacy of the visual in landscapes see: B. Bender, 'Stonehenge - contested landscapes (medieval to the present-day)', in B. Bender, ed., Landscape, Politics and Perspectives, Providence, 1993, pp.245-79; D. Cosgrove, 'Prospect, perspective and the evolution of the landscape idea', Transactions of the Institute of British Geographers, 10 (1985). pp.45-62; D. Crouch and N. Ravenscroft. 'Culture, social difference and the leisure experience: the example of consuming countryside', in G. McFee, W. Murphy \& G. Whannel, eds, Leisure Cultures: Values, Genders, Lifestyles, Eastbourne, 1995, pp.289-302; N. Green, 'Looking at the landscape: class formation and the visual', in E. Hirsch \& M. O'Hanlon, eds, The Anthropology of Landscape: Perspectives on Place and Space, Oxford, 1995, pp.31-42; P. Macnaghten and J. Urry. Contested Natures, London, 1998; K. Thomas, Man and the Natural World: Changing Attitudes in England 1500-1800, London, 1983; J.Urry, The Tourist Gaze, London, 2002.

9 C. Alexander. 'The garden as occasional domestic space', Signs, 27, 3 (2002), pp.857-71.

10 R. Barnett, Garden Style in New Zealand, Auckland, 1993, p.73.

11 Alexander, p.864.

12 This has clear parallels with Urry's argument that the eye relegates objects to a safe distance and renders them passive. J. Urry, 'Sensing leisure spaces', in D. Crouch, ed., Leisure/Tourism Geographies: Practices and Geographical Knowledge, London, 1999, pp.34-45. 


\section{Journal of New Zealand Studies}

13 B.S. Turner and J. Edmunds, 'The distaste of taste: Bourdieu, cultural capital and the Australian postwar elite', Journal of Consumer Culture, 2, 2 (2002), pp.219-40; Bourdieu, Distinction.

14 K. Fox, Watching the English: The Hidden Rules of English Behaviour, London, 2004, pp.132-3.

I5 J. Codd, 'Making distinctions: the eye of the beholder', in R. Harker, C. Mahar \& C. Wilkes, eds., An Introduction to the Work of Pierre Bourdieu: The Practice of Theory, London, 1990, pp.132-59.

16 P. Bourdieu, 'The field of cultural production, or: the economic world reversed', Poerics, 12 (1983), pp.311-56.

17 Bourdieu, Distinction, pp.56-8.

18 S.W. Foster, 'Reading Pierre Bourdieu', Cultural Anthropology, 1, 1 (1986), pp.103-110.

19 O. Löfgren, 'The empire of good taste: everyday aesthetics and domestic creativity', in B. Klein \& M. Widbom, eds, Swedish Folk Art: All Tradition is Change, Stockholm, 1994, pp.235-46.

20 R. Bendix, 'Gartenästhetik: anmerkungen zum Umgang mit Aussenräumen in den USA', in H. Nikitsch \& B. Tschofen, eds, Volkskunst, Vienna, 1995, pp.281-99.

21 B.S. Pollock, 'Designing Residential Gardens: With More Reference to the Influence of House Design and Placement upon Garden Layout', New Zealand National Diploma of Horticulture, Lincoln University, 1976, p.69.

22 C. Bell and J. Lyall, 'Aesthetic leisure', in C. Bell, ed., Sociology of Everyday Life in New Zealand, Palmerston North, 200I, pp.150-64.

23 P. Thompson, 'Dress to impress', New Zealand Gardener, June (2004), pp.82-5.

24 M. Bligh, 'Designing your garden', in New Zealand Pocket Gardening Encyclopedia, Auckland, (2002), p.29.

25 J. Brooks, Garden Plans: New Designs for Small Gardens, London, 1988, p.332.

26 H. Leach, Cultivating Myths: Fiction, Fact \& Fashion in Garden History, Auckland, 2000 , p.55.

27 A. Barker, 'Alfrescotips: A-Z dictionary', Your Home \& Garden, February (2002), pp.96-100.

28 C. Bucknell, 'Essentially Kiwi', New Zealand Gardener, Special Edition, 1 (2001), p.23.

29 R. Wypych, 'Easy does it', Your Hone \& Garden, June (2004), pp.106-8.

30 B. Probert, 'How we shape the garden', in P. Timms, ed., The Nature of Gardens, St. Leonards, 1999, pp.59-89.

31 Ibid., pp.62-3

32 Green, pp.40-1.

33 John Barrell notes that historically there have been class-differentiated ways of seeing landscape. Burrell suggests that in eighteenth-century Britain there was an opposition between the 'panoramic prospect' and the 'occluded view'. The panoramic prospect is surveyed, organised and understood by disinterested public men, who regard the objects in the landscape always as representative ideas, intended to categorise rather than to imitate their originals in nature, and who study not the objects themselves, but their relations. They are enabled to do this by their ability to abstract, and by their ability to comprehend and classify (J. Barrell, 'The public prospect and the private view: the politics of taste in eighteenth-century Britain', in S. Pugh, ed., Reading Landscape: Country, City, Capital, Manchester, 1990, pp.19-40). On the other hand, the occluded view is narrow, conceals distance, and sees objects in and for themselves as objects of consumption and possession without understanding their relations to each other (S. Pugh, 


\section{Decks and Other Distinctions}

'Introduction: stepping out into the open', in S. Pugh, ed., Reading Landscape: Country, City, Capital, Manchester, 1990, pp.1-6). This may explain the middle-class aim of an overall picture in contrast to the working class 'patchwork' style of gardening.

34 Green, pp.40-41.

35 Fox, p.130.

36 N. Garnham, 'Extended review: Bourdieu's Distinction', Sociological Review, 34, 2 (1986), pp.423-33.

37 Bourdieu, Distinction, p.57.

38 Löfgren, p.246.

39 Codd, p.142.

40 G. Simmel, 'Fashion', American Sociology, 62, 6 (1957), p.541.

41 Bourdieu, Distinction, p.57.

42 D. Miller. 'Style and ontology', in J. Friedman, ed., Consumption and Identity, Harwood, 1994, pp.71-96.

43 Bourdieu, Distinction, p.6. 